\title{
Rice varietal selection in Bangladesh: Does it matter who in the farm household makes the decisions?
}

\author{
Toritseju Begho $\mathbb{D}$ \\ Rural Economy, Environment \& Society, Scotland's Rural College (SRUC), Peter Wilson Building, King's Buildings, W Mains \\ Rd, Edinburgh EH9 3JG UK \\ Corresponding author. Email: Toritseju.Begho@sruc.ac.uk
}

(Received 30 June 2021; revised 18 August 2021; accepted 17 September 2021; first published online 19 October 2021)

\begin{abstract}
This paper examines whether rice adoption decision differs between sole decision-making and collaborative decision-making in which household members jointly decide on rice varietal selection. Overall, the results show that the majority of rice farmers currently cultivate older rice varieties. The average varietal age is 22 years. Adopters and non-adopters are significantly different in several observed characteristics; however, most of the differences are small. Specifically, between adopter and non-adopters, there is a statistically significant difference in the average varietal age of rice grown, the number of plots owned, varietal trait preferences, seed sources, contact with agricultural extension agents and risk preference. The results of the double-hurdle regression estimation are unconvincing for a difference between household decisionmaking structures, indicating that it does not matter who in the farm household makes the decisions on rice varietal selection. To encourage the adoption of improved rice varieties and reduce the average varietal age, the focus should be on improving access to agricultural land and extension contact. Besides, aligning varietal trait with farmers' preferences and organising farm demonstrations is crucial.
\end{abstract}

Keywords: Adoption; Bangladesh; Household; Decision-making; Rice; Varietal selection

\section{Introduction}

Rice is the staple food for the people of Bangladesh and a strategic crop for ensuring food security (Uddin and Dhar, 2018). With a fast-growing population and increasing vulnerability to climate change, rice production needs to keep up to demands. Before the release of improved rice varieties, much of the increase in rice production is attributed to the expansion of agricultural land area (Hossain et al., 2006). Currently, little scope exists for an increase in production merely through acreage expansion. Despite the potential of improved rice varieties to resolve the issue, adoption of improved rice varieties is low regardless of government and non-government agencies investing substantial resources to produce varieties with high yield potential and resistance to various stresses (Ahmed et al., 2016).

To investigate the reasons for low levels of adoption of improved rice varieties, several studies (e.g. Hossain et al. 2006; Malabayabas et al., 2014; Mottaleb et al., 2015) have been carried out to identify the factors that influence adoption. Broadly classified, these studies have found the characteristics of the farmer and farm household, the farm biophysical, financial and management characteristics and exogenous factor such as prices to affect farmers' adoption. However, the determinants of rice adoption in Bangladesh are still not fully investigated. For instance, little is known about how adoption is affected by the composition of the household decision-makers. 
The literature on rice adoption in Asia is growing. So far, the overarching finding is that adoption of improved rice varieties is low and slow. In South Asia, low varietal replacement rates result in high average varietal ages. Gauchan et al. (2011) examined the adoption of improved rice varieties in South Asia and found a significant number of farmers adopted improved varieties released prior to 1990 with fewer farmers adopting newer varieties released after 1990. Gauchan et al. (2011) attributed these findings of low adoption of newer improved varieties to the lack of the desired varietal attributes specifically not having much improvement in yield and profitability of the newer varieties. In their study, Mottaleb et al. (2015) found that adoption varied across regions in Bangladesh with only around $15 \%$ of the household in their study at most adopted hybrid rice in 2008 .

For rice to meet future demand, curtailing adoption lag is crucial. Hossain et al. (2006) observed that farmers still cultivated rice varieties that were released over three decades. Specifically, they found that the variety that was predominantly grown in the wet season in Bangladesh as of 2000 was the BR11 which was released in 1980. Malabayabas et al. (2014) found that even in flood-prone areas, the adoption rates are low for two varieties submergence-tolerant rice varieties - BRRI dhan51 and BRRI dhan52. Similarly, Gauchan and Pandey (2012) reported that the area allocated to older improved rice varieties (released prior to 1990) was approximately 94, 62 and $60 \%$ in India, Bangladesh and Nepal, respectively.

Comparing varietal age between two time periods (2011 and 2008) in Nepal, Witcombe et al. (2017a) results show that after accounting for several factors, the average rice varietal age did not change between the periods considered. This suggests that farmers are not adopting newer rice varieties as quickly as they are released. Witcombe et al. (2017a; 2017b) also noted that among the widely grown varieties spanning $76 \%$ of rice area, only two were below 15 years with the others averaging over 20 years. However, it is not all bleak as Janaiah and Xie (2010) result shows some promise as the adoption rate of hybrid rice increased from less than $1-3.2 \%$ area planted between 1996 and 2008.

Most of these studies (e.g. Mottaleb et al. (2015) and Hossain et al. (2006) in Bangladesh; Ghimire et al. (2015) in Nepal, Bannor et al. (2020) in India) examined and found one or more significant effect of variables such as age, gender, level of education, farming experience, soil characteristics, ownership of land and farm machinery, seed regulation and access to extension services on the adoption of rice varieties. However, none of these studies considered whether adoption is influenced by the household decision-making structure.

Regarding gender aspects, there is no consensus on the effect of gender on the adoption decision of farmers. The role of gender in varietal adoption is specifically scarce on decisions related to crop varietal adoption. For example, Mehar et al. (2017) find that in India, male farmers compared to female farmers are less likely to select hybrid rice. Some studies have postulated that the differences in the choice between men and women are mainly related to the expectations of the benefit of adopting the new varieties. Hellin et al. (2010) conclude that while men were more interested in making extra income from adopting high yielding varieties, women focused on nutritious varieties and labour reducing varieties with good processing and storing abilities. According to Gebre et al. (2019) in households, men and women do not always have an identical level of access to inputs and information as a result decision-making choices may differ by gender. Tanellari et al. (2014) find that the likelihood of adoption of crop improved varieties was lower among female-headed households. This paper identifies two gaps in this aspect. First, most of these studies did not examine cases where the decision on variety adoption was made jointly and secondly most of the studies did not consider decision taken by a spouse (that is not the household head) on behalf of the household.

This paper, therefore, is set against the background of decisions taken at the farm household level by different household members and the apparent implications for the adoption of improved rice varieties in Bangladesh. Decision-making is an integral part of rice farmers' day-to-day life and whether the decisions are made solely or jointly the outcomes may have consequences at the 
household level. The decision to adopt improved rice varieties by farm households could be crucial to household food availability and possibly improve the livelihoods of farmers. This paper examines whether rice adoption decision differs between sole decision-making (either by the household head or their spouse) and collaborative decision-making in which case the household members jointly take the decision. The contribution of this paper to the literature is from two perspectives. This paper fills important research gaps in the adoption literature by proceeding beyond investigating determinants of adoption of improved crop varieties to examining the factors that influence adoption lag and specifically, contributes to the continuing debate on household composition as a determinant of crop varietal selection.

\section{Theoretical background}

The section focuses on providing an overview of underlying household decision theories, empirical finding concerning farm household decision-making and adoption of improved rice varieties in South Asia.

\section{Definitions of adoption and the household}

Peterman et al. (2014) referred to adoption as when an individual or group of people that could be classified as a unit use input or method for the first time whether or not it is within the context of an established program. However, defining a farmer that is an 'adopter' come with complexities as the term has been used in various context across several studies. For instance, Doss (2006) observed that in some cases farmers that used saved seeds that had hybrids origin were classified as adopters while in other cases those that used only new certified seed were categorised as adopters. In line with Gebre et al. (2019), this paper defines adopters as farmers that cultivated new improved rice varieties either solely or with other rice varieties. Similar to the classification of Hossain et al. (2006) and Gauchan et al. (2011), this paper groups 'new generation' improved rice varieties to include improved varieties released after the 1990s primarily released for their yield potential, improved resistance to pest and diseases and improved grain quality. The justification for this arises from empirical evidence that there is widespread cultivation of older improved varieties with considerably large adoption lags of about 12-20 years (see Gauchan and Pandey, 2012).

In terms of defining agricultural households, at least one member of the household should currently be operating a holding, or the respondent, household head or main income provider earns income from agriculture (United Nations statistical office, 1984). The context in which the household head is used in this paper signifies an individual whom other household members recognise to be responsible for managing and organising the household.

In this paper, joint decisions refer to decision made after an agreement is reached by all participating parties of the same household which differs from sole decision-making where the decision is taken by a single household member. This paper however does not consider the bargaining or procedure involved before the decision is made.

\section{Household decision models}

The most popular neoclassical static model is known as the 'unitary' utility household model. The unitary model centres on the assumptions that households act like a single decision-maker. This indicates that there is a single household welfare function that accounts for the preferences of all household members. In modelling household behaviour using the unitary model, a widely used approach is Samuelson (1956) consensus model which assumes maximising a single utility function that incorporates individual household members' utilities. It accounts for household members having their preferences but the household utility function collapses to a unitary one. Becker (1976) altruist model on the other hand assumes that the household acts as one unit under the 
guidance of an altruist 'dictator' who takes into consideration the welfare of other household members as reflected in their utility function. Despite the advantage this model holds in terms of simplicity of specification, its plausibility however has been questioned as it does not accommodate divergences of interest among members of a household.

Addressing some of the concerns of the unitary model are both the cooperative and noncooperative models. The non-cooperative models posit that a decision-maker does not cooperate but rather take measures targeted at maximising self-utility functions, that is, household members have different preferences and behave as autonomous subunits. In the real world, however, this assumption is impracticable in the context of a household which result in many intra-household decision studies favouring models that consider cooperation instead, that is, where the household members maximise its joint utility function. For the non-cooperative models, the results do not always result in efficiency. Household members consider the actions of other members when they voluntarily provide household public goods with consequences that the equilibrium is Nash type without the guarantee of Pareto efficiency. The stability of the bargaining outcome is fundamental to the difference between the cooperative and non-cooperative models. For the former, when that the spouse bargaining power remains the same the cooperative models can be assumed to remain stable. For the latter, however, there is the possibility of a shift in the equilibrium with additional information regarding the spouse's position and strength at disposal.

In low- and middle-income countries, it is scarce to find cases where spouses have the same preferences and equal access to resources. These differences could affect decision-making power. Studies have shown that the preferences of household member are not always homogenous, and each member has their utility function with varying abilities to impact decision outcomes (Iversen et al. 2011). The implication of heterogeneous preferences in a household is that members may resort to intra-household bargaining. Fiala and $\mathrm{He}$ (2017) study is empirical evidence that both unitary and non-cooperative models can be observed in households and no single household decision model can wholly explain household decision-making.

This paper draws on the aforementioned collective models in which case the assumption is that when farming decisions are made jointly, the household members recognise the benefits that can be obtained from adopting the new improved rice varieties so will make a decision that will maximise the utility of the household. However, when the decision is made solely by a household member on behalf of the household the decision-maker tends to act according to the predictions of traditional models and seek to maximise the sole decision-maker's own utility function.

\section{Empirical finding on farm household decision-making and adoption decisions}

It is still a subject of debate whether the outcome of decisions made jointly is better than decisions individuals take solely. According to Story and Burgard (2012), joint decision-making was more likely to result in a better outcome compared to sole decision-making specifically because there is more scope to appraise different options when making decision jointly. In a non-farm setting, Koriat (2012) find that if one or more of the individual members making a joint decision is not adequately skilled and also lacks the necessary information needed to make a decision, it could result in outcomes that are negative or unfavourable.

Studies have identified management as well as productivity differences in farms individually and jointly managed to range from input used to the yield. Marenya et al. (2015) results show that jointly managed plots use more fertiliser for maize and fruit and vegetable and less for non-food cash crops compared to solely managed fields plots. The authors also find that jointly managed plots were more likely to adopt improved agroecological practices. Comparing sole with joint decision-makers, Brown (2019) found that the adoption of novel technologies was higher among male sole decision-makers compared to joint decision-makers and for females, the reverse was true. Bjornlund et al. (2019) in contrary findings observed that compared to men, women adopted high-value crops for the sake of improving their lives and livelihood. Brown (2019) 
opined that these differences could arise from (male) sole decision-makers being more risk tolerant than joint decision-makers.

\section{The study area}

Rice is the staple food in Bangladesh. It occupies about $77 \%$ of the total cropped area and accounts for $93 \%$ of the annual total food grains (BER 2013; Uddin and Dhar 2018). Over the last three decades, the contribution of improved rice varieties to growth in rice yield is estimated at $2.3 \%$ per year (Hossain et al., 2006). Bangladesh unique location makes it particularly vulnerable to climate change which affects rice yield. This is manifested in several abiotic stresses that characterise rice production across the country. For instance, drought is a common problem especially in the North-western region of the country. The coast and northeast are exposed to flooding and soils in coastal areas are affected by salinity.

Rice is cultivated in three cropping seasons. The main rice crop is Aman which is monsoon rice that is usually planted in April-May and harvested in November-December. Boro is dry season irrigated rice cultivated in planted in December-February and harvested in April-May and Aus is planted in March-April and harvested in July-August (Hossain et al., 2006). On average in 2017/ 2018, the yield of Aman, Aus and Boro rice was 2.19, 2.13 and $3.98 \mathrm{t} \mathrm{ha}^{-1}$, respectively (Hasan and Rahman, 2019).

Many of the rice varieties grown across the three cropping seasons have peculiar attributes as shown in Table 1. For instance, some are mainly characterised by higher yields while others are resistant to various stresses. For instance, BRRI dhan52 is Aman rice with some tolerance to submergence, BRRI dhan 42 is Aus rice tolerant to drought while BRRI dhan64 is nutrient-enriched Boro rice.

Notably, the yield gap remains an issue in Bangladesh (Mondal, 2011; Khan et al., 2013). Averaged over 2016-2019, Assefa et al. (2021) estimated the yield gap within improved varieties at around $30 \%$. While farmers may adopt improved varieties, believing that the choice would result in better prospect, in reality, the actual yield may be much less than the yield potential considering heterogeneity in research plots and farmers' plots. Khan et al. (2013) and Barua et al. (2014) are among the studies that provide a detailed assessment of the yield potential and actual yield of improved rice varieties in South Asia.

The study areas made up of Barisal, Chittagong, Dhaka, Khulna, Rajshahi and Rangpur consist of the main rice-growing regions across Bangladesh with regards yield and production (Dasgupta et al., 2018). These areas are also heterogeneous in terms of socio-economic and biophysical conditions (Awal, 2015).

\section{Methods}

The paper assumes that households make two decisions. One with respect to the adoption of improved rice varieties and the other in terms of varietal age since release - a proxy used to examine varietal turnover. Drawing from the findings in the literature, the hypothesis in this paper is that although rice farmers in Bangladesh may have adopted improved varieties, the varieties adopted are mostly those that have been released many years earlier, resulting in varietal turnover constituted by high varietal age. Assuming farmers are faced with the decision regarding adopting a new rice variety a farmer will aim to maximise his/her utility subject to certain budget constraints. Similar to Gebre et al. (2019), the adoption decision can be modelled using a random utility framework given as:

$$
G_{i}^{*}=\beta X_{i}^{\prime}+v_{i} \text { where } G_{i}^{*}= \begin{cases}1 & \text { if } G_{i}^{*}>0 \\ 0 & \text { Otherwise }\end{cases}
$$

$\beta$ and $X_{i}$ are the vectors of the unknown parameters and explanatory variables, respectively while $v_{i}$ is the error term. $G_{i}^{*}$ designates the latent variable that corresponds to the difference 
Table 1. Selected improved rice varieties by cropping season

\begin{tabular}{|c|c|c|c|}
\hline \multirow[b]{2}{*}{ Characteristics } & \multicolumn{3}{|c|}{ Cropping season } \\
\hline & Boro & Aus & Aman \\
\hline Salinity & $\mathrm{Bd} 47, \mathrm{Bd} 61, \mathrm{Bd} 67$ & & $\begin{array}{l}\text { BR23, Bd40, Bd41, Bd53, Bd54, } \\
\text { Bd73 }\end{array}$ \\
\hline Submergence & & & $\begin{array}{l}\text { Bd51, Bd52, Bd79, BINA dhan } 11 \text {, } \\
\text { BINA dhan } 12\end{array}$ \\
\hline Drought & & $\mathrm{Bd} 42, \mathrm{Bd} 43, \mathrm{Bd} 48$ & $\mathrm{Bd} 56, \mathrm{Bd} 57, \mathrm{Bd} 66, \mathrm{Bd} 71$ \\
\hline Nutrient enriched & $\mathrm{Bd} 64, \mathrm{Bd} 74, \mathrm{Bd} 84$ & & Bd62, Bd72 \\
\hline $\begin{array}{l}\text { Disease and pest } \\
\text { resistance }\end{array}$ & BR17, BR18, BR19 & $\begin{array}{l}\text { BR20, BR21, BR24, Bd42, } \\
\text { Bd43, Bd65, Bd83 }\end{array}$ & \\
\hline High yielding & $\begin{array}{l}\text { Bd58, Bd59, Bd60, Bd68, } \\
\text { Bd69, Bd81, Bd88. }\end{array}$ & $\mathrm{Bd} 48$ & BR11 \\
\hline Grain length & $\mathrm{Bd} 60$ & & \\
\hline Aromatic rice & $\mathrm{Bd} 50$ & & $\begin{array}{l}\text { BR5, Bd34, Bd37, Bd38, Binadhan- } \\
9 \text {, and Binadhan- } 13\end{array}$ \\
\hline
\end{tabular}

Bd, BRRI dhan.

Source: Bangladesh Rice Research Institute (BRRI, 2016); Shelley et al. (2016).

between the expected utility from adopting the new improved rice variety represented by $U^{a}$ and from non-adoption by $U^{n a}$. If $G_{i}^{*}=U^{a}-U^{n a}>0$ then should the farmer be utility maximising, the farmer will choose to adopt the improved rice variety.

Given that there are two problems to be examined, the Cragg (1971) double-hurdle model is employed in this paper. The flexibility of the double-hurdle model over the Tobit model enables the model to account for the possibility that there may be differences in determinants of adoption of improved rice varieties and determinants of the age of the improved rice varieties currently grown, that is, varietal turnover. Specifically, the double-hurdle model is made up of two equations known generally as the 'first' and 'second' hurdles. The former takes into account that a subset of farmers may not adopt improved rice varieties while the latter models the age of the improved rice varieties adopted. In this case, the assumption is that the decision to adopt improved rice varieties and the decision on the age of improved variety are separate albeit inter-related. This paper follows Bannor et al. (2020) that applied the double-hurdle model in similar adoption studies in South Asia.

Assuming $y_{i}$ denote the observed age of improved rice varieties

$$
\begin{gathered}
y_{i}=\left\{\begin{array}{cc}
x_{i} \beta+\epsilon_{i} & \text { if } \min \left(x_{i} \beta+\epsilon_{i}, z_{i} \gamma+u_{i}\right)>0 \\
0 & \text { Otherwise }
\end{array}\right. \\
\left(\begin{array}{l}
\epsilon_{i} \\
u_{i}
\end{array}\right) \sim N(0, \Sigma), \Sigma=\left(\begin{array}{ll}
1 & \sigma_{12} \\
\sigma_{12} & \sigma^{2}
\end{array}\right)
\end{gathered}
$$

The log-likelihood function for the double-hurdle model is specified by

$$
\begin{aligned}
\log (L)= & \sum_{y_{i}=0}\left[\log \left\{1-\Phi\left(z_{i} \gamma, \frac{x_{i} \beta}{\sigma}, \rho\right)\right\}\right] \\
& +\sum_{y_{i}>0}\left(\log \left[\Phi\left\{\frac{z_{i} \gamma+\rho / \sigma\left(y_{i}-x_{i} \beta\right)}{\sqrt{1-\rho^{2}}}\right\}\right]-\log [\sigma]+\log \left\{\varnothing\left(\frac{y_{i}-x_{i} \beta}{\sigma}\right)\right\}\right)
\end{aligned}
$$

where the CDF of a bivariate normal with correlation $\rho$ is represented by $\Psi(x, y, \rho)$. The special case when the double-hurdle model corresponds to the Tobit model is when $\rho=0$ and taking the limit $z_{i} \gamma \rightarrow+\infty$. As such the double-hurdle model reduces to the Tobit log-likelihood (García, 2013). 
In the case of Tobit model (Tobin, 1958) assuming the dependent variable $y$ takes continuous positive values, but $P(\mathrm{y}=0)>0$ and $P(\mathrm{y}<0)=0$. Where $\Phi($.$) is the standard normal cumulative$ distribution function and $\phi($.$) represent the standard normal density function. The log-likelihood$ of the Tobit model corresponds to

$$
\log (L)=\sum_{y_{i}=0}\left[\log \left\{1-\Phi\left(\frac{x_{i} \beta}{\sigma}\right)\right\}\right]+\sum_{y_{i}>0}\left[\log \left\{\varnothing\left(\frac{y_{i}-x_{i} \beta}{\sigma}\right)\right\}-\log (\sigma)\right]
$$

However, a restriction is imposed on the underlying stochastic process by the Tobit functional form so that the choice of $y_{i}>0$ and the value of $\mathrm{y}$, given that $y_{i}>0$, is estimated by the same vector of parameters $x_{i} \beta$. As a result, when the signs (of the effect of a covariate on the probability of adoption and the effect of the same covariate on the age of improved rice varieties) are different, the Tobit model is incapable of adequately handling such cases. Given these attributes, this paper postulates that the double-hurdle model could provide a better estimation than the Tobit model because it allows separate stochastic processes for the adoption and duration decisions. However, this assumption is tested, and for comparison, the results of the double-hurdle and Tobit regressions are presented.

\section{Data and sample size}

The study used data from the 2014 South Asia Rice Monitoring Survey (RMS-SA). The survey was conducted by the International Rice Research Institute with funding from the Bill and Melinda Gates Foundation and contains detailed information on DNA fingerprinting and varietal mapping. Farmers were selected through multistage sampling. First was a random selection of 150 villages after which 10 farm households were randomly selected. In total, the data set included responses from 1500 respondents of which 1480 were used in this study. The 20 farmers whose responses were excluded were mainly due to either incomplete responses or responses not relevant to the present study. In addition to rice farmers' characteristics, farm structure, cropping activities and farmers' preferences, the data also contained information on farmers risk preference determined by Eckel and Grossman (2008) type experiment.

\section{Results and Discussions}

The majority of farmers still cultivate older improved or traditional rice varieties with the average age across (traditional, older and newer improved) varieties being 22 years. Approximately $33 \%$ of farmers adopted newer improved rice varieties. Recall that new improved rice varieties in this paper are classified as those improved varieties released after 1990. Notably, farmers that changed their rice varieties have been growing new their current improved rice varieties for about 5 years on average; however, the age of adopted new improved varieties was 15 years on average. One reason for this low adoption of new improved rice varieties could be attributed to varietal misidentification by farmers which have consequences on seed production and distribution. Farmers have been observed to mix up varieties and erroneously grow another variety in place of the desired variety. Also, this aligns with previous concerns (e.g. Lojo, 2018) that some seeds purchased from the open market are deliberately or unintentionally mixed up and given wrong labels with no protocols for establishing the actual identities of the varieties.

As shown in Table 2, in terms of improved rice varieties, those with age of 20 years since release (e.g. BRRI dhan 32, BRRI dhan 30, BRRI dhan 29, BRRI dhan 28 and BRRI dhan 27) recorded the highest proportion (65.9\%) in the count of adopted improved rice varieties. Specifically, the two most widely cultivated improved rice varieties are BRRI dhan 28 and BRRI dhan 29 which accounted for the rice cultivated by 13 and $7 \%$, respectively of the total rice varieties grown. This finding corroborates Alam et al. (2010). The main attributes of the BRRI dhan 28 are its early maturity, moderate resistance to rice blast and yield potential of approximately 6 tons 
Table 2. Distribution of adopted improved rice varieties by varietal age

\begin{tabular}{|c|c|c|}
\hline Variety name & $\begin{array}{l}\text { Frequency of adopted improved } \\
\text { rice varieties }\end{array}$ & $\begin{array}{l}\text { Percentage of adopted improved } \\
\text { rice varieties }\end{array}$ \\
\hline $\begin{array}{l}\text { Varietal age }=1 \text { year since release } \\
\text { Binadhan-11 (Ciherang Sub } 1) \text {, Binadhan-12 } \\
\quad \text { (Samba Masuri) }\end{array}$ & 4 & 0.3 \\
\hline $\begin{array}{l}\text { Varietal age }=2 \text { years since release } \\
\text { Binadhan-10 }\end{array}$ & 3 & 0.2 \\
\hline $\begin{array}{l}\text { Varietal age }=3 \text { years since release } \\
\text { Bd57, Bd55 }\end{array}$ & 24 & 1.6 \\
\hline $\begin{array}{l}\text { Varietal age }=4 \text { years since release } \\
\text { Binadhan-8, Bd52 (BR11 Sub 1), Bd51 } \\
\quad \text { (Swarna Sub 1) }\end{array}$ & 131 & 8.6 \\
\hline $\begin{array}{l}\text { Varietal age }=6 \text { years since release } \\
\text { Bd50, Bd49, Bd48 }\end{array}$ & 107 & 6.9 \\
\hline $\begin{array}{l}\text { Varietal age }=7 \text { years since release } \\
\text { Binadhan- } 7, \text { Bd } 47\end{array}$ & 152 & 9.8 \\
\hline $\begin{array}{l}\text { Varietal age }=9 \text { years since release } \\
\text { Bd44 }\end{array}$ & 16 & 1.0 \\
\hline $\begin{array}{l}\text { Varietal age }=11 \text { years since release } \\
\mathrm{Bd} 40, \mathrm{Bd} 41\end{array}$ & 32 & 2.1 \\
\hline $\begin{array}{l}\text { Varietal age }=15 \text { years since release } \\
\text { Bd39 }\end{array}$ & 16 & 1.0 \\
\hline $\begin{array}{l}\text { Varietal age }=17 \text { years since release } \\
\text { Bd33 }\end{array}$ & 32 & 2.1 \\
\hline $\begin{array}{l}\text { Varietal age }=20 \text { years since release } \\
\mathrm{Bd} 32, \mathrm{Bd} 30, \mathrm{Bd} 29, \mathrm{Bd} 28, \mathrm{Bd} 27\end{array}$ & 1023 & 65.9 \\
\hline $\begin{array}{l}\text { Varietal age }=21 \text { years since release } \\
\text { Bd26 }\end{array}$ & 10 & 0.6 \\
\hline Total & 1553 & 100 \\
\hline
\end{tabular}

$\mathrm{Bd}=\mathrm{BRR}$ dhan, $N=1562$ because most households adopted more than one improved rice varieties. ${ }^{*}$ Percentage of adopted improved rice varieties is obtained by adding the percentage of all varieties of the same age. For instance, the percentage of rice varieties that are 1 year since release (as at 2014) is the sum of the individual percentages of Binadhan-11 and Binadhan-12 resulting in $0.3 \%$.

per hectare. BRRI dhan 29 on the other hand has a higher yield potential averaging 7.5 tons per hectare and is moderately resistant to leaf blight and sheath.

Tables 2 and 3 highlight the relationships between the adopted frequency of varieties and their crop traits. It is evident that farmers prefer to retain older improved or traditional rice varieties which are high yielding but may not necessarily be stress tolerant. However, this observation does not account for preferences such as profitability from higher straw price, good yield under delay planting dates, taste or higher milling outturn which may also influence the adoption decisions.

The characteristics between adopters and non-adopters of new improved rice varieties are compared in Table 4 . The Chi square and $t$-test statistics suggest that non-adopters and adopters are significantly different in several observed characteristics. However, most of the differences between adopters and non-adopters are very small. The average varietal age of rice grown by adopters is 15.7 years which is statistically significantly lower than 35.5 years for non-adopters. Adopters had a statistically significantly higher number of plots, had a higher percentage that had been in contact with agricultural extension agents, used less of their seeds saved from previous seasons and are more risk tolerant. Although there is significant difference, for example, in the household head solely ( $\mathrm{HH}$ solely) however, the $p$ of 0.01 is attributable to the large sample size. Besides, from a practical perspective, this is non-significant as the difference is about $1 \%$.

Concerning desired attributes, $54 \%$ of adopter mentioned high yield as the trait they like about the variety they currently grow which is higher than $35 \%$ reported by non-adopters. Across both groups, most of the respondents were male having an average age of about 45 years. The majority 
Table 3. Comparison of traits of selected rice varieties

\begin{tabular}{|c|c|c|c|c|}
\hline Variety name & Yield (t/ha) & Days to maturity & Grain quality & Resistance/tolerance \\
\hline \multicolumn{5}{|l|}{ New improved } \\
\hline Binadhan-11 (Ciherang Sub 1) & $\begin{array}{l}4.5^{\mathrm{a}} \\
5.4^{\mathrm{b}}\end{array}$ & $135^{\mathrm{a}}, 120^{\mathrm{b}}$ & Medium long & Submergence tolerant \\
\hline Binadhan-12 (Samba Masuri) & $\begin{array}{c}4.0^{\mathrm{a}} \\
4.5^{\circ}\end{array}$ & $145^{\mathrm{a}}, 130^{\mathrm{b}}$ & Medium short & Submergence tolerant \\
\hline Binadhan-10 & 8.0 & 132 & Medium long & Salt tolerant, resistant to major pest and diseases \\
\hline Bd57 & 4.5 & 110 & Medium slender & Drought tolerant \\
\hline Bd55 & 7.0 & 100 & Medium slender & Drought tolerant \\
\hline Binadhan-8 & 4.5 & 135 & Medium bold & Salt tolerant, moderately resistant to pest and diseases \\
\hline $\begin{array}{l}\text { Bd51 } \\
\quad \text { (Swarna Sub 1) }\end{array}$ & 4.5 & 142 & Medium slender & Submergence tolerant \\
\hline $\mathrm{Bd} 49$ & 5.5 & 128 & Medium bold & \\
\hline $\mathrm{Bd} 48$ & 5.5 & 110 & Medium bold & \\
\hline Binadhan-7 & 5.5 & 120 & Fine & Tolerant to major insect-pests \\
\hline $\mathrm{Bd} 47$ & 6.5 & 152 & Medium bold & Salt tolerant \\
\hline $\mathrm{Bd} 40$ & 4.5 & 145 & Medium bold & Salt tolerant \\
\hline $\mathrm{Bd} 41$ & 4.5 & 148 & Long bold & Salt tolerant \\
\hline $\mathrm{Bd} 39$ & 4.5 & 122 & Fine & \\
\hline $\mathrm{Bd} 33$ & 4.5 & 118 & Short bold & Drought tolerant \\
\hline $\mathrm{Bd} 32$ & 5.0 & 130 & Medium bold & \\
\hline $\mathrm{Bd} 30$ & 5.0 & 145 & Medium slender & \\
\hline $\mathrm{Bd} 29$ & 7.5 & 160 & Medium slender & \\
\hline $\mathrm{Bd} 28$ & 5.0 & 140 & Medium slender & \\
\hline $\mathrm{Bd} 27$ & 4.0 & 115 & Medium bold & \\
\hline $\mathrm{Bd} 26$ & 4.0 & 115 & Fine & \\
\hline \multicolumn{5}{|l|}{ Older improved /Traditional } \\
\hline BR11 (Mukta) & 6.5 & 145 & Medium bold & Moderately resistant to Tungro and tolerant to Yellow Stem Borer \\
\hline BR16 & 6.0 & 165 & Medium slender & \\
\hline BR10 (Progati) & 6.5 & 150 & Medium slender & Tolerant to several diseases, moderately tolerant to yellow stem borer \\
\hline BR23 & 5.5 & 150 & Long slender & Moderately salt tolerant \\
\hline GutiSwarna & 4.8 & 150 & Medium bold & \\
\hline
\end{tabular}

aunder 20-25 days submerged condition, ${ }^{a}$ No submergence.

Source: Hossain M, Bose ML, Mustafi BA (2006); Digital Herbarium of Crop Plants (2016); Ahmed et al. (2016). 
Table 4. Comparison of characteristics between adopters and non-adopters of new improved rice varieties

\begin{tabular}{|c|c|c|c|c|}
\hline \multirow[b]{2}{*}{ Characteristics } & \multirow{2}{*}{$\begin{array}{l}\text { Non-adopter } \\
(\mathrm{N}=992) \\
\text { Percent (freq.) }\end{array}$} & \multirow{2}{*}{$\begin{array}{c}\begin{array}{c}\text { Adopter } \\
(\mathrm{N}=488)\end{array} \\
\text { Percent (freq.) }\end{array}$} & \multicolumn{2}{|c|}{ Test for association } \\
\hline & & & $\chi^{2}$ & $p$-value \\
\hline \multicolumn{5}{|l|}{ Household decision-maker(s) ${ }^{a}$} \\
\hline HH solely & 79.5 (787) & 78.6 (382) & 9.025 & $0.011^{\star \star}$ \\
\hline $\mathrm{HH}$ and spouse jointly & $16.9(167)$ & $14.4(70)$ & & \\
\hline $\mathrm{HH}$ and parent jointly & $3.6(36)$ & $7.0(34)$ & & \\
\hline \multicolumn{5}{|l|}{ Gender } \\
\hline Male & $84.0(833)$ & 83.9 (409) & 0.006 & 0.937 \\
\hline Female & $16.0(159)$ & $16.1(79)$ & & \\
\hline \multicolumn{5}{|l|}{ Marital status } \\
\hline Married & $94.0(932)$ & $94.8(462)$ & 0.310 & 0.577 \\
\hline Otherwise & $6.0(60)$ & $5.2(26)$ & & \\
\hline \multicolumn{5}{|l|}{ Variety trait } \\
\hline High yield & $35.4(351)$ & $54.0(263)$ & 46.167 & $<0.001^{\star \star *}$ \\
\hline Others & $64.6(641)$ & $46.4(225)$ & & \\
\hline \multicolumn{5}{|l|}{ Education } \\
\hline No schooling & $12.8(127)$ & $13.1(64)$ & 0.028 & 0.866 \\
\hline Otherwise & $87.2(865)$ & $86.9(424)$ & & \\
\hline \multicolumn{5}{|l|}{ Had extension contact } \\
\hline Yes & $84.4(837)$ & $89.7(438)$ & 7.931 & $0.005^{\star \star \star}$ \\
\hline No & $15.6(155)$ & $10.3(50)$ & & \\
\hline \multicolumn{5}{|l|}{ Attended demonstration } \\
\hline Yes & $61.9(614)$ & $58.9(287)$ & 1.306 & 0.253 \\
\hline No & $38.1(378)$ & $41.1(201)$ & & \\
\hline \multicolumn{5}{|l|}{ Use own seed } \\
\hline Yes & $76.1(755)$ & $61.1(298)$ & 36.059 & $<0.001^{\star \star *}$ \\
\hline No & $23.9(237)$ & $38.9(190)$ & & \\
\hline \multicolumn{5}{|l|}{ Never changed variety } \\
\hline Yes & 72.5 (719) & $60.8(297)$ & 20.517 & $<0.001^{\star * *}$ \\
\hline No & $27.5(273)$ & $39.2(191)$ & & \\
\hline Varietal age (years) $^{\mathrm{b}}$ & $32.5(3.8)$ & $15.7(6.5)$ & 61.183 & $<0.001^{\star \star \star}$ \\
\hline Age (years) ${ }^{\mathrm{b}}$ & $44.9(13.3)$ & $45.0(12.7)$ & -0.136 & 0.446 \\
\hline Plot owned (number) ${ }^{b}$ & $2.5(2.1)$ & $2.9(2.0)$ & -3.459 & $<0.001^{\star * *}$ \\
\hline Risk tolerance (number) ${ }^{\mathrm{b}}$ & $3.1(1.4)$ & $3.3(1.2)$ & -2.678 & $0.004^{\star *}$ \\
\hline
\end{tabular}

Significant at ${ }^{\star \star \star} 1,{ }^{\star \star} 5$ and ${ }^{\star} 10 \%$.

Chi square test used unless otherwise noted.

aThe categories 'spouse solely' and 'others' were dropped due to insufficient numbers (i.e. one adopter and non-adopter each).

${ }^{\mathrm{b}}$ Mean, corresponding standard deviation reported and $t$-test results.

of respondents were married and had primary education at the very least. This description is in line with previous findings (e.g. Hossain et al., 2006).

In response to the question 'Who in your household makes decisions on rice variety selection?', the statistics show that among non-adopters, the decision on the choice of rice varieties was mainly taken by the household head solely as it accounted for $79 \%$ while $16 \%$ was household head and spouse jointly and $3 \%$ was household head and parent jointly. On the other hand, for adopters, the proportion was 78,14 and $7 \%$ for the household head solely, the household head and spouse jointly and the household head and parent jointly respectively. These statistics corroborate previous studies that find that among farming household, cooperative decision-making model is not widespread particularly in intra-household production decisions. A summary of the results indicates a household where the decision on rice variety selection was by the household head and spouse jointly had the highest varietal age among adopters.

The results in Table 5 summarise the estimates of double-hurdle and Tobit regression models. The dependent variable is whether farmers adopted improved rice varieties. To check for multicollinearity, a diagnostic test was carried out using the variance inflation factor (VIF). The VIF result values between 1.00 and 1.34 suggest that multicollinearity was not an issue among the 
Table 5. Double-hurdle (Probit and Truncated) and Tobit regressions results of factors that influence the adoption of new improved rice varieties

\begin{tabular}{|c|c|c|c|c|c|c|}
\hline & \multicolumn{4}{|c|}{ Double hurdle } & \multirow{2}{*}{\multicolumn{2}{|c|}{ Tobit }} \\
\hline & \multicolumn{2}{|c|}{$\begin{array}{l}\text { Probit (decision to } \\
\text { adopt new improved } \\
\text { rice varieties) }\end{array}$} & \multicolumn{2}{|c|}{$\begin{array}{l}\text { Truncated regression } \\
\text { (varietal turnover } \\
\text { proxied by age of } \\
\text { improved rice) }\end{array}$} & & \\
\hline & Coeff. & SE & Coeff. & SE & Coeff. & SE \\
\hline \multicolumn{7}{|l|}{ Household decision-maker ${ }^{a}$} \\
\hline Household head and spouse jointly & $-0.511^{\star \star}$ & $(0.506)$ & -0.110 & $(0.056)$ & $-1.834^{\star}$ & $(1.000)$ \\
\hline Household head and parent jointly & $-0.834^{\star}$ & $(0.787)$ & 0.176 & $(0.095)$ & 2.716 & $(1.669)$ \\
\hline Gender (male) & -0.695 & $(0.522)$ & 0.052 & $(0.058)$ & 0.525 & $(1.043)$ \\
\hline Age (years) & -0.005 & $(0.016)$ & -0.000 & $(0.002)$ & -0.009 & $(0.031)$ \\
\hline Marital status $(1=$ married $)$ & 0.138 & $(0.093)$ & 0.932 & $(0.865)$ & $2.896^{\star}$ & $(1.669)$ \\
\hline Education ( $1=$ no schooling) & -0.102 & $(0.530)$ & 0.029 & $(0.059)$ & 0.490 & $(1.057)$ \\
\hline Variety trait (high yield) & $0.140^{\star \star \star}$ & $(0.353)$ & 0.460 & $(0.039)$ & $8.101^{\star \star \star}$ & $(0.711)$ \\
\hline Number of plot owned & $0.199^{\star \star \star}$ & $(0.089)$ & $0.051^{\star \star}$ & $(0.010)$ & $0.967^{\star \star \star}$ & $(0.175)$ \\
\hline Extension contact (yes) & $0.397^{\star \star \star}$ & $(0.598)$ & 0.194 & $(0.061)$ & $3.606^{\star \star \star}$ & $(1.115)$ \\
\hline Attended demonstration (yes) & -1.113 & $(0.369)$ & $-0.030^{\star \star \star}$ & $(0.042)$ & -1.086 & $(0.745)$ \\
\hline Risk preference & $0.802^{\star \star \star}$ & $(0.144)$ & $0.095^{\star \star \star}$ & $(0.015)$ & $2.017^{\star \star \star}$ & $(0.278)$ \\
\hline Intercept & $13.602^{\star \star \star}$ & $(1.424)$ & $-1.374^{\star \star \star}$ & $(0.148)$ & $-24.53^{\star \star \star}$ & $(2.738)$ \\
\hline Log-likelihood & -2853.52 & & -5047.45 & & -8393.37 & \\
\hline Sigma & $6.610^{\star \star \star}$ & $(0.134)$ & & & & \\
\hline \multicolumn{7}{|c|}{$\chi^{2}$ test Double-Hurdle versus Tobit, $\lambda=-984.80>\chi^{2}(12)=26.22$} \\
\hline
\end{tabular}

Significant at ${ }^{* \star *} 1,{ }^{* *} 5$ and ${ }^{*} 10 \%$. Standard error in parenthesis.

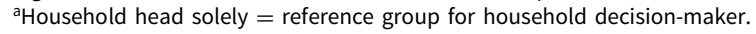

predictors. A likelihood-ratio test was conducted to determine whether the double hurdle is the most suitable for the study. A restriction test was carried out using the log-likelihood values obtained from a separate estimation of Tobit, Probit and Truncated regression models. The results of the likelihood ratio test $\left[\chi^{2}(14)=-984.80 ; p<0.001\right]$ indicate that the double-hurdle model is preferred over the Tobit model. Besides, decisions based on the Bayesian and Akaike's information criteria support the finding that the double-hurdle model performs better than the Tobit model. The Wald test for the double-hurdle model is significant at $1 \%$ indicating that the null hypothesis specifying that the set of explanatory variables in the model simultaneously equal to zero should be rejected. Recognising possible issues arising from varietal age in terms of the distribution of the values being positively skewed, the data are transformed using a natural logarithm to ensure its validity under the censored normal distribution assumption. The results however do not differ from estimation with direct responses.

The results in Table 5 show that not all the factors that influence the adoption of new improved rice varieties also have a statistically significant effect on varietal age. Also, the signs of the coefficient were similar for both the double-hurdle and Tobit models, but the variables that had a significant effect on adoption differed between the models.

\section{Factors affecting adoption of new improved rice varieties}

In Table 5, the results of the Probit model are unconvincing for a difference between household decision-making structures as the coefficients are low and the statistical significance is either at the 5 or $10 \%$ level. Besides, there is no statistically significant effect of the household decision-maker in the Tobit model at the $5 \%$ level. This finding does not conform with some previous findings, for example, Koriat (2012) reported that when individual members making a joint decision are adequately skilled and have the necessary information needed to make a decision, the outcomes are usually positive. However, the results suggest that differences in farm and farmer attributes order 
than household decision-making structures are more important determinants of rice varietal selection; hence, these attributes should be the focus of intervention.

The number of plots owned had a significant positive effect on the adoption of improved rice varieties. Farmer with a greater number of self-owned plots demonstrates a higher probability to adopt improved varieties. This corroborates Paltasingh (2018) on the effect of land tenure on the adoption of improved rice varieties. One credible assumption is that farmers that own their plots have no limitation on the duration of years they can farm on the land. They are also not restricted to the crop variety to grow as with the case of sharecropping and do not face the risk of returning the land to the landlord. Thus, they are more likely to adopt new crop varieties which they can spread the cost of adoption across several years to benefit them over the long run.

Yield as a desirable trait had a significant positive effect on the adoption of improved rice varieties. If a variety has the potential for good yield compared to other positive traits, the chances to adopt improved varieties increased. Since yield is usually an important trait which farmers in the region consider, they are more likely to adopt rice varieties that show promise of increased yield although not without considering other desirable traits. As noted by Hossain et al. (2006), varieties released in Bangladesh after 1990 focused on attributes such as shorter plants in regard to height, with a few with potential to produce higher yield potentials. To meet farmers' need, rice variety developers need to consider that even in the case where farm household has adequate information regarding the new rice variety, farmers' evaluation of and need for certain attributes may differ from that of developers. Thus, consulting with farm household is important in the design of new improved rice varieties. It is worth mentioning that the quality of the rice and consumer/market preference for sensory/aroma/texture/purpose of use, etc. are important factors for adoption; however, these were not individually considered as the paper focused on the single most important attribute (as reported by respondents). This aspect warrants examination in future studies.

As expected a priori risk preference had a significant positive effect on the adoption of improved rice varieties. Greater risk tolerance increases the chances of adopting improved varieties. This reinforces previous studies that risk-tolerant farmers tend to adopt technology and innovations quicker than their risk-neutral or risk-intolerant counterpart. This is mainly because they worry less about the cost of uncertainty and of learning associated with adopting new technology. It is worth stating that since risk preference is attitude specific, the conclusion that risk-tolerant farmers tend to adopt technology may not necessarily hold for different attributes, for example, varietal stress tolerance compared to yield potential.

\section{Factors determining the varietal turnover}

Overall, plot ownership, risk preference and attendance of demonstration were found to be significant determinants of the age of rice variety cultivated as shown in the truncated regression in Table 5. Specifically, plot ownership had a significant positive effect on the age of improved varieties adopted. The more number of plots owned by the farmer the higher the chances the farmer will grow older improved rice varieties. Although this finding does not conform with priori expectations, it may be that the fragmented and scattered plots vary in agroecological conditions; thus, farmers grow more varieties across the plots to reduce risk. In this case, switching to newer improved varieties will be more challenging or may have different opportunity cost compared to those with fewer plots.

For risk preference, the model suggests that the varietal age of adopted improved varieties is positively affected by being more risk tolerant. One possible explanation is, if the main attribute for which the newer improved rice varieties are released is a risk-reducing attribute, then the risktolerant farmer may not adopt the improved varieties. Besides, this may also be because risktolerant farmers generate positive externalities for late adopters. Thus, they may want to recoup the accrued cost of uncertainty and learning associated with the initial adoption of improved varieties. 
Attending demonstration had a significant effect on the varietal age of adopted improved rice varieties. For farmers that attended farm demonstrations, the expected chance that they grow more recent improved varieties is higher than those that did not attend a demonstration. This aligns with Freeman et al. (2002) and Morse and McNamara (2003). One plausible reason for this could be that the concerns of risk associated with adopting a new technology reduce by observing the new varieties in fields and conditions very similar to theirs and possibly demonstrated by farmers within their network. More so, demonstration broadens understanding and most importantly provides farmers with proof of comparison of the benefits of the new varieties over the varieties which they currently grow.

\section{Conclusion}

This paper examines factors that influence the adoption of new improved rice varieties and primarily focused on the difference between household decision-making structures as a determinant of the adoption of new improved rice varieties. The result confirms that considering separately the stochastic processes describing the decision to adopt improved rice varieties and the varietal age of adopted varieties is crucial in identifying the effect different variables have on rice varietal selection and varietal age. The findings suggest that there is practically no difference between household decision-making structures in terms of the adoption of new improved rice varieties. To encourage the adoption of improved rice varieties and reduce the average varietal age, the focus should be on improving access to agricultural land and extension contact. Besides, aligning varietal traits with farmers' preferences through an institutional arrangement that permits interactions between individual farmers or farm households and scientists on desired attributes at variety development stage is necessary. Also, organising local farm demonstrations is crucial.

Acknowledgements. The author would like to thank Yamano Takashi and team for making the data publicly available.

Funding. The author received no financial support for the research, authorship, and/or publication of this article.

Competing Interests. The author declare that there is no conflict of interest.

\section{References}

Ahmed A.U., Hernandez R. and Naher F. (2016). Adoption of Stress-Tolerant Rice Varieties in Bangladesh. In Technological and Institutional Innovations for Marginalized Smallholders in Agricultural Development. Cham: Springer, pp. 241-255.

Alam M.S., Quayum M.A. and Islam M.A. (2010). Crop production in the Haor areas of Bangladesh: insights from farm level survey. The Agriculturists 8, 88-97.

Assefa Y, Yadav S, Mondal M.K., Bhattacharya J., Parvin R., Sarker S.R., Rahman M., Sutradhar A., Prasad P.V.V., Bhandari H., Shew A.M. and Jagadish S.V.K. (2021). Crop diversification in rice-based systems in the polders of Bangladesh: yield stability, profitability, and associated risk. Agricultural Systems 187, 102986.

Awal M.A. (2015). Climate changes over Bangladesh Delta: II. Extreme weather events and their consequences. American Journal of Environmental Engineering and Science 2, 65-76.

Bannor R.K., Kumar G.A., Oppong-Kyeremeh H. and Wongnaa C.A. (2020). Adoption and impact of modern rice varieties on poverty in Eastern India. Rice Science 27, 56-66.

Barua R., Islam A.G.S.R.M. and Biswash M.R. (2014). Contemporary yielding knowledge of rice cultivation at grassroots level-a study. Journal of Eco-Friendly Agriculture 7, 61-64.

Becker G.S. (1976). Altruism, egoism, and genetic fitness: economics and sociobiology. Journal of Economic Literature 14, $817-826$.

BER. (2013) Bangladesh Economic Review, Finance Division, Ministry of Finance, Government of the People's Republic of Bangladesh, Dhaka; 2013. 6-225

Bjornlund H., Zuo A., Wheeler S.A., Parry K., Pittock J., Mdemu M. and Moyo M. (2019). The dynamics of the relationship between household decision-making and farm household income in small-scale irrigation schemes in southern Africa. Agricultural Water Management 213, 135-145.

Brown P (2019) Gender Educational Attainment and Farm Outcomes in New Zealand Land. Land 8, 18.

BRRI Annual Report (2016-2017). Bangladesh Rice Research Institute, Gazipur-Bangladesh 
Cragg J.G. (1971). Some statistical models for limited dependent variables with application to the demand for durable goods. Econometrica: Journal of the Econometric Society 39, 829-844.

Dasgupta S., Hossain M.M., Huq M. and Wheeler D. (2018). Climate change, salinization and high-yield rice production in coastal Bangladesh. Agricultural and Resource Economics Review 47, 66-89.

Digital Herbarium of Crop Plants (2016). Retrieved on August 14, 2021 from http://dhcrop.bsmrau.net/3894-2/?doing_wp_ cron=1629191146.6320369243621826171875

Doss C.R. (2006). Analyzing technology adoption using microstudies: limitations challenges and opportunities for improvement Agricultural Economics 34, 207-219.

Eckel C.C. and Grossman P.J. (2008). Forecasting risk attitudes: an experimental study using actual and forecast gamble choices. Journal of Economic Behavior \& Organization 68, 1-17.

Fiala N. and He X. (2017). Unitary or noncooperative intrahousehold model? Evidence from couples in Uganda The World Bank Economic Review 30 Supplement_1, S77-S85 https://doiorg/101093/wber/lhw011

Freeman H.A., Van der Merwe P.J.A., Subrahmanyam P., Chiyembekeza A.J. and Kaguongo W. (2002). Experimental Agriculture 38, 211-221. doi: 10.1017/S0014479702000261

García B. (2013). Implementation of a double-hurdle model. The Stata Journal 13, 776-794.

Gauchan D., Bool R., Malabayabas M. and Pandey S. (2011). Adoption pattern of new generation modern rice varieties in stress-prone environments of South Asia (No 2232-2019-2322).

Gauchan D and Pandey S (2012). Synthesis of key results and implications In S Pandey, D Gauchan, M Malabayabas, M BoolEmerick and B Hardy (eds), Patterns of Adoption of Improved Rice Varieties and Farm-level Impacts in Stress-Prone Rainfed Areas in South Asia. Los Baños Philippines: International Rice Research Institute, pp. 1-18.

Gebre G.G., Isoda H., Amekawa Y. and Nomura H. (2019). Gender differences in the adoption of agricultural technology: The case of improved maize varieties in southern Ethiopia In Women's Studies International Forum (Vol 76 p 102-264) Pergamon.

Ghimire R., Huang W.C. and Shrestha R.B. (2015). Factors affecting adoption of improved rice varieties among rural farm households in Central Nepal. Rice Science 22, 35-43.

Hasan M.M. and Rahman M.M. (2019). Simulating climate change impacts on T. aman (BR-22) rice yield: a predictive approach using DSSAT model. Water and Environment Journal 34, 250-262.

Hellin J., Keleman A. and Bellon M. (2010). Maize diversity and gender: research from Mexico. Gender \& Development 18, 427-437.

Hossain M., Bose M.L. and Mustafi B.A. (2006). Adoption and productivity impact of modern rice varieties in Bangladesh. The Developing Economies 44, 149-166.

Iversen V., Jackson C., Kebede B., Munro A. and Verschoor A. (2011). Do spouses realise cooperative gains? Experimental evidence from rural Uganda. World Development 39, 569-578.

Janaiah A. and Xie F. (2010). Hybrid rice adoption in India: Farm level impacts and challenges IRRI Technical Bulletin No 14.

Khan A.M.R., Anwar M.M., Akter S. and Prodhan M.Z.H. (2013). Identification of factors influencing yield gaps in mustard, potato and rice in some selected areas of Bangladesh and strategies to minimize the gaps. Bangladesh Journal of Agricultural Research 38, 227-240.

Koriat A. (2012). When are two heads better than one and why? Science 336, 360-362.

Lojo K. (2018). DNA fingerprinting to improve seed systems monitoring in Bangladesh, 2018. Retrieved March 12, 2021 from http://news.irri.org/2018/05/dna-fingerprinting-to-improve-seed.html

Malabayabas M., Yamano T. and Noor T. (2014). Adoption of submergence-tolerant rice varieties BRRI dhan51 and BRRI dhan52 in northern Bangladesh. STRASA Economic Brief, IRRI Bill and Melinda Gates Foundation 1-4.

Marenya P., Kassie M. and Tostao E. (2015). Fertilizer use on individually and jointly managed crop plots in Mozambique. Journal of Gender Agriculture and Food Security (Agri-Gender) 1, 62-83.

Mehar M., Yamano T. and Panda A. (2017). The Role of Gender Risk and Time Preferences in Farmers' Rice Variety Selection in Eastern India Asian. Journal of Agriculture and Development 14, 17-36.

Mondal M.H. (2011). Causes of yield gaps and strategies for minimizing the gaps in different crops of Bangladesh. Bangladesh Journal of Agricultural Research 36, 469-476.

Morse S. and McNamara N. (2003). Factors affecting the adoption of leguminous cover crops in Nigeria and a comparison with the adoption of new crop varieties. Experimental Agriculture 39, 81.

Mottaleb K.A., Mohanty S. and Nelson A. (2015). Factors influencing hybrid rice adoption: a Bangladesh case Australian Journal of Agricultural and Resource Economics 59, 258-274.

Paltasingh K.R. (2018). Land tenure security and adoption of modern rice technology in Odisha Eastern India: Revisiting Besley's hypothesis. Land Use Policy 78, 236-244.

Peterman A., Behrman J.A. and Quisumbing A.R. (2014). A review of empirical evidence on gender differences in nonland agricultural inputs technology and services in developing countries In Gender in agriculture (pp 145-186) Springer Dordrecht.

Samuelson P.A. (1956). Social indifference curves. The Quarterly Journal of Economics 70, 1-22. 
Shelley I.J., Takahashi-Nosaka M., Kano-Nakata M., Haque M.S. and Inukai Y. (2016). Rice cultivation in Bangladesh: present scenario, problems, and prospects. Journal of International Cooperation for Agricultural Development 14, 20-29.

Story W.T. and Burgard S.A. (2012). Couples' reports of household decision-making and the utilization of maternal health services in Bangladesh. Social Science \& Medicine 75, 2403-2411.

Tanellari E., Kostandini G., Bonabana-Wabbi J. and Murray A. (2014). Gender impacts on adoption of new technologies: the case of improved groundnut varieties in Uganda African. Journal of Agricultural and Resource Economics 9, 300-308.

Tobin J. (1958). Estimation of relationships for limited dependent variables. Econometrica: journal of the Econometric Society 24-36.

Uddin M.T. and Dhar A.R. (2018). Government input support on Aus rice production in Bangladesh: impact on farmers' food security and poverty situation. Agriculture \& Food Security 7, 14.

United Nations Statistical Office (1984) Handbook of Household Surveys Revised Edition Studies in Methods Series F No 31 United Nations New York 1984 para 1315.

Witcombe J.R., Khadka K., Puri R.R., Khanal N.P., Sapkota A. and Joshi K.D. (2017a) Adoption of rice varieties-I Age of varieties and patterns of variability. Experimental Agriculture 53, 512-527.

Witcombe J.R., Khadka K., Puri R.R., Khanal N.P., Sapkota A. and Joshi K.D. (2017b). Adoption of rice varieties. 2. Accelerating uptake. Experimental Agriculture 53, 627-643.

Cite this article: Begho T (2021). Rice varietal selection in Bangladesh: Does it matter who in the farm household makes the decisions?. Experimental Agriculture 57, 255-269. https://doi.org/10.1017/S0014479721000211 